\title{
THE EFFECT OF ELECTRIC FIELD CONFIGURATION ON THE THERMO-CHEMICAL CONVERSION OF STRAW PELLETS
}

\author{
I. Barmina*, A. Kolmickovs, R. Valdmanis, S. Vostrikovs, M. Zake \\ Institute of Physics, University of Latvia, \\ 32 Miera Str., Salaspils, LV-2169, LATVIA, \\ *e-mail: barmina@sal.Iv
}

With the aim to control and improve the thermo-chemical conversion of straw pellets, the experimental investigations of the DC electric field effect on the combustion dynamics and heat energy production were made. The electric field effect on the gasification/combustion characteristics was studied using three different positions of the positively charged electrode in flame. First, the electrode was positioned coaxially downstream the flame flow. Next, the electrode was positioned coaxially upstream the flame flow and, finally, the electrode was positioned across the downstream flow. The bias voltage of the electrode varied in the range from 0.6 up to $1.8 \mathrm{kV}$, while the ion current in flame was limited to $5 \mathrm{~mA}$. The results of experimental investigations show that the DC electric field intensifies the thermal decomposition of straw pellets and enhances mixing of volatiles with air causing changes in combustion dynamics and heat energy production, which depend on position and the bias voltage of the electrode. The increase in the average volume fraction of $\mathrm{CO}_{2}$ (by $6 \%$ ) and the decrease in the mass fraction of unburned volatiles in the products ( $\mathrm{CO}$ by $60 \%$ and $\mathrm{H}_{2}$ by $73 \%$ ) for the upstream field configuration of the electrode and the ion current $0.5-1.8 \mathrm{~mA}$ indicate more complete combustion of volatiles.

Keywords: electric field, composition emissions, heat energy, straw pellets, thermochemical conversion.

\section{INTRODUCTION}

The EC 2030 climate and energy targets for the period from 2021 to 2030 require more efficient use of renewable fuels (har- vesting, agriculture or herbaceous residues) for energy production (by $32 \%$ ) to reduce greenhouse emissions (GHG) by $40 \%$ 
and to improve energy efficiency by $32 \%$ [1]. The use of renewable fuels for energy production is related to the formation of "carbon-neutral" emissions by limiting the formation of GHG emission during their thermochemical conversion [2], while it can cause the problems, which are associated with their relatively low heating value, high nitrogen and ash contents, low melting temperatures of ash and relatively high content of heavy metals in biomass, especially in agriculture and herbaceous residues [3], [4]. Different methods and technologies have been developed to improve their combustion characteristics, such as washing, drying, sieving, leaching, granulation, thermal pre-treatment or mw pre-treatment [4]-[6]. The effective tool for an increase in the applicability of problematic renewable fuels (straw, herbaceous residues) for more efficient heat energy production with the reduced $\mathrm{NO}_{\mathrm{x}}, \mathrm{CO}$ emission is their cofiring with solid [7]-[9] or gaseous fossil or renewable fuels [7]. Besides, the effective control of the thermochemical conversion of biomass and the main combustion characteristics can be obtained using the electric effects on the flame, which can be related to the field-enhanced mass transfer of the flame ions and neutral species in the field direction, determining local variations of the flame temperature and composition [10], [11]. It should be noticed that the electric field-induced variations of the main flame characteristics are observed if the DC and AC electric fields are applied to different flame types (laminar, turbulent) during the combustion of gaseous fuels [10]-[13]. Limited number of experiments were per- formed to assess the electric field effect on the thermochemical conversion of biofuels, when the field-enhanced interrelated processes of heat and mass transfer promoted the thermal decomposition of biofuels (wood, straw pellets), the formation of combustible volatiles $\left(\mathrm{CO}, \mathrm{H}_{2}\right)$, their mixing with air, ignition and burnout [14], [15]. Moreover, the results of industrial experiments suggest that the electric field effects on the flame can be used to control the processes developing in the industrial combustion systems [16] determining cleaner and more efficient heat energy production.

The results of complex experimental study and mathematical modelling of DC electric field effects on the thermochemical conversion of solid fuels (straw, wood, peat and their mixtures) confirm that the electric field effects on the flame can be used to improve mixing of the flame components, to control the formation of the flow dynamics, the main flame characteristics, heat energy production and composition of emissions, depending on a lot of factors, such as bias voltage of the electrodes, their configuration and location [14], [15]. With account of the influence of these factors on the thermochemical conversion of biofuels, the goal of this study is to optimise the configuration of the electrodes, their location in the flame reaction zone and potential to achieve the effective control of the gasification/combustion characteristics, produced heat energy and composition of the emission at thermochemical conversion of problematic biofuel - straw pellets with the aim to provide more efficient use of straw as fuel for energy production.

\section{EXPERIMENTAL}

The experimental study of the electric field effect on the thermochemical conversion of wheat straw pellets was studied using a batch-size pilot device with the heat output up to $4 \mathrm{~kW}$. The experimental device included biomass gasifier (1) and 
two-sections of the water-cooled combustor (2) with inner diameter $88 \mathrm{~mm}$ and 600 mm of total height (Fig. 1). The gasifier was charged with fixed mass (450 g) of A-quality wheat straw pellets with $9.1 \%$ moisture content. The propane flame flow was used for an additional heat $(0.81 \mathrm{~kW})$ input into the device to initiate the thermal decomposition of straw pellets and the formation of combustible volatiles $\left(\mathrm{CO}, \mathrm{H}_{2}\right)$ and was switched off after ignition of volatiles. The primary air (3) was supplied at the bottom of the gasifier at the constant rate of $30 \mathrm{l} /$ min and was used to support the gasification of straw pellets. The secondary swirling air (4) was supplied above pellet layer at the constant rate of $40 \mathrm{1} / \mathrm{min}$ and was used to provide the combustion of volatiles downstream the combustor. The diagnostic sections with openings (5) were used for the local measurements of the flow velocity, flame temperature and composition of products. With the aim to provide DC electric field control of the thermochemical conversion of wheat straw pellets, nichrome wire electrodes with the diameter of $3 \mathrm{~mm}$ (7) were located in the flame base, where the peak values of the flame primary flame ions
$\left(\mathrm{CHO}^{+}, \mathrm{C}_{2} \mathrm{H}_{3}^{+}, \mathrm{H}_{3} \mathrm{O}^{+}\right.$, etc.) were observed [14]. The experimental study of the electric field effect on the gasification/combustion of wheat straw pellets was provided for three different configurations of the electrodes. First, the electrode of length $\mathrm{L}=94$ $\mathrm{mm}$ was inserted through the layer of straw pellets and was positioned axially downstream the flame flow up to the flame reaction zone (Fig. 1, a). Next, the electrode of length $53 \mathrm{~mm}$ was inserted into the flame reaction zone at distance $\mathrm{L}=65 \mathrm{~mm}$ from secondary air supply through the opening in the wall of the combustor and was positioned axially upstream of the flame flow (Fig. 1, b). Finally, the electrode of length $40 \mathrm{~mm}$ was inserted into the flame reaction zone at distance $\mathrm{L}=65 \mathrm{~mm}$ from secondary air supply through the opening in the wall of the combustor and was positioned across the flame flow (Fig. 1, c). The electric field was applied in the space between the electrode and water-cooled walls of the device. The positive bias voltage of the electrode relative to the water-cooled walls could be varied in the range from 0.6 to $1.8 \mathrm{kV}$ by limiting the ion current in the flame to 5 $\mathrm{mA}$.

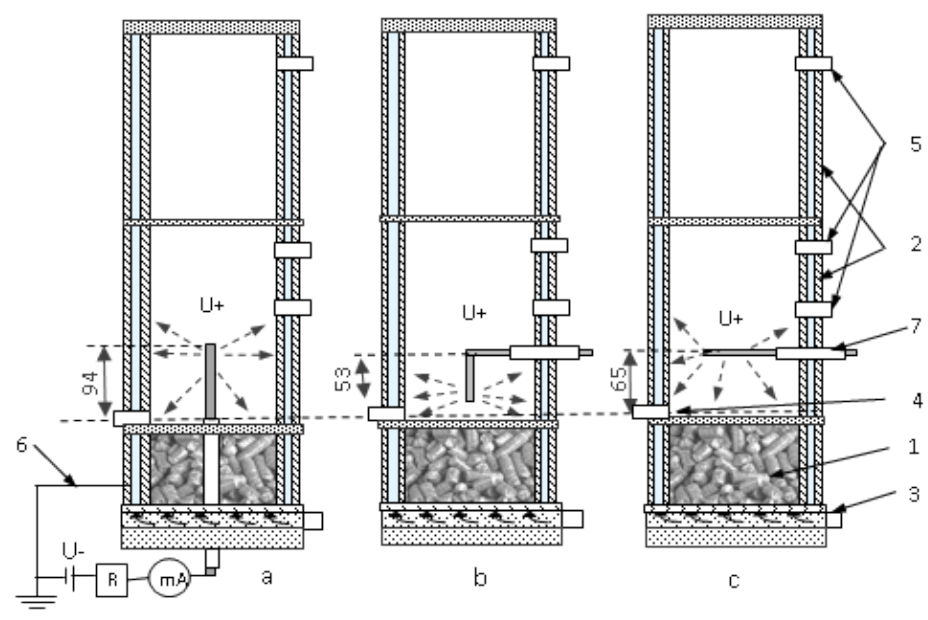

Fig. 1. The laboratory scale device for experimental study of the DC electric field effect on the thermochemical conversion of straw pellets: 1. gasifier, 2. water-cooled sections of the combustor, 3. primary air supply nozzle,

4. secondary swirling air supply nozzle, 5. diagnostic sections with orifices, 6. electric measuring circuit, 7. electrode placement: a- electrode arranged axially downstream of the flow; b- electrode arranged axially upstream of the flow; c- electrode arranged across the flow. 
The detailed studies of the DC electric field effect on the thermal decomposition of straw pellets and combustion of volatiles involve the measurements of the weight loss rates of straw pellets, the local measurements of the axial and tangential flow velocity components, the kinetic and radial measurements of the flame temperature, the calorimetric measurements of the cooling water flow from the gasifier and the combustor, the local measurements of the flame composition and composition of polluting emissions. Detailed methodology of the experiments was described in [14].

\section{RESULTS AND DISCUSSION}

The experimental study of the DC electric field effect on the combustion dynamics and variations of the main combustion characteristics starts with the estimation of the effect of electrode arrangement on the main flame characteristics at the condition $\mathrm{U}=0$. The results of experimental measurements of the flame velocity and tempera-
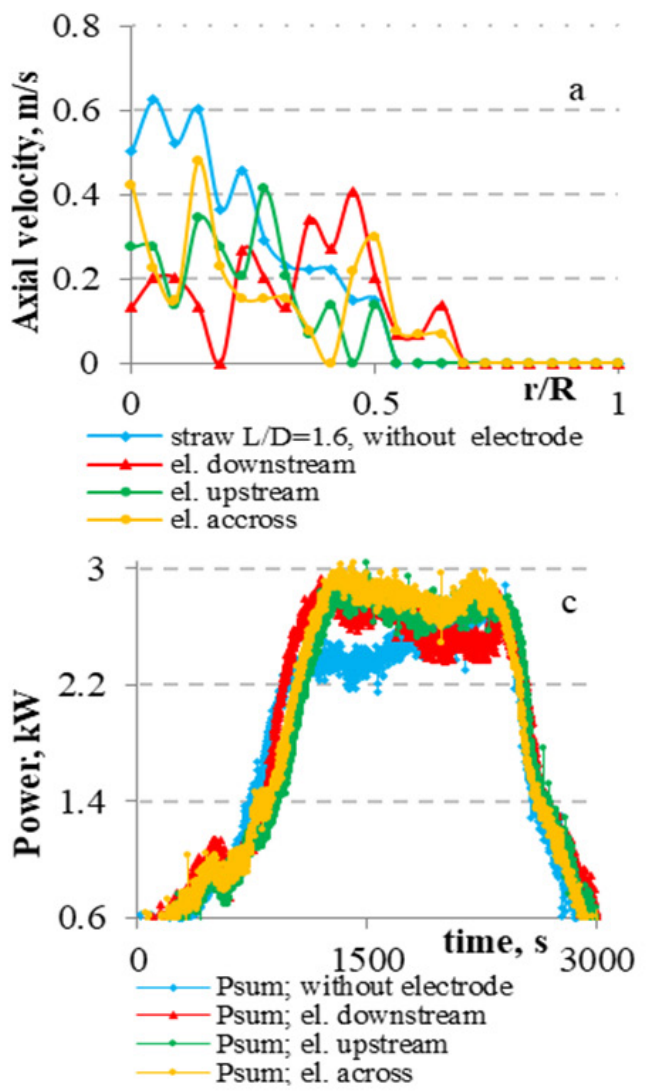

ture formation field have shown that for all positions of the electrode (downstream, upstream, across) its placement in the flame flow disturbs the formation of the flame temperature and velocity profiles decreasing the average values of the axial velocity with radial expansion of the flow velocity and flame temperature profiles (Fig. 2-a, b).
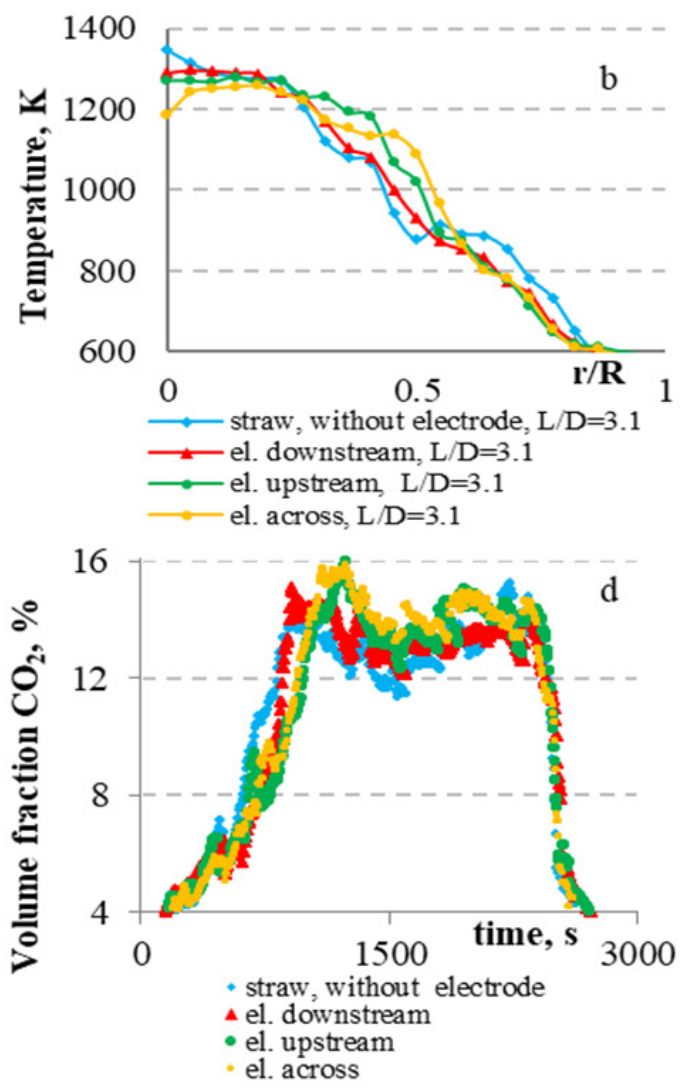

Fig. 2. The effect of the electrode arrangement on the flow axial velocity (a), flame temperature (b) profiles, the total heat output from the device (c) and the volume fraction of $\mathrm{CO}_{2}$ in the products (d). 
Moreover, the time-dependent measurements of the total heat output from the device and the volume fraction of $\mathrm{CO}_{2}$ in the products (Fig. 2, c-d) confirm that for all electrode configurations inserting the electrode into the flame flow promotes the enhanced burnout of volatiles. Further changes in the main flame characteristics are achieved by increasing the positive bias voltage of the electrode and the current in the flame space between the electrodes, which depends on the formation of flame ions. During the burnout of hydrocarbon fuels the formation of the main flame ions $\left(\mathrm{CHO}^{+}, \mathrm{H}_{3} \mathrm{O}^{+}, \mathrm{C}_{3} \mathrm{H}_{3}^{+}\right)$refers to the development of the chemo-ionization reactions between the flame species:

$$
\begin{aligned}
& \mathrm{CH}+\mathrm{O} \rightarrow \mathrm{CHO}^{+}+\mathrm{e} \\
& \mathrm{CH}^{*}+\mathrm{C}_{2} \mathrm{H}_{2} \rightarrow \mathrm{C}_{3} \mathrm{H}_{3}^{+}+\mathrm{e}
\end{aligned}
$$

$$
\begin{aligned}
& \mathrm{C}_{2} \mathrm{H}+\mathrm{O}_{2}{ }^{*} \rightarrow \mathrm{CO}+\mathrm{CHO}^{+}+\mathrm{e} \\
& \mathrm{CHO}^{+}+\mathrm{H}_{2} \mathrm{O} \rightarrow \mathrm{CO}+\mathrm{H}_{3} \mathrm{O}^{+}
\end{aligned}
$$

$\mathrm{H}_{3} \mathrm{O}^{+}$is accepted as the major positive ion [17]. The concentration of positive ions in hydrocarbon/air flames is about $10^{17}-10^{18}$ $\mathrm{m}^{-3}$. During the thermochemical conversion of straw pellets the maximum value of ion density $\left(\mathrm{n}_{\mathrm{i}} \approx 1.8 * 10^{17} \mathrm{~m}^{-3}\right)$ was observed in the central part of the flame reaction zone, close to the flow axis $(\mathrm{r} / \mathrm{R}<0.3)$ at distance $\mathrm{L} / \mathrm{D} \approx 1-1.5$ from the flame base (Fig. 3, a). Therefore, to achieve the most effective field-induced control of the main flame characteristics, the electric field must be applied to this part of the flame flow. The current-voltage characteristics for three different locations of the electrode in the flame are presented in Fig. 3, b.
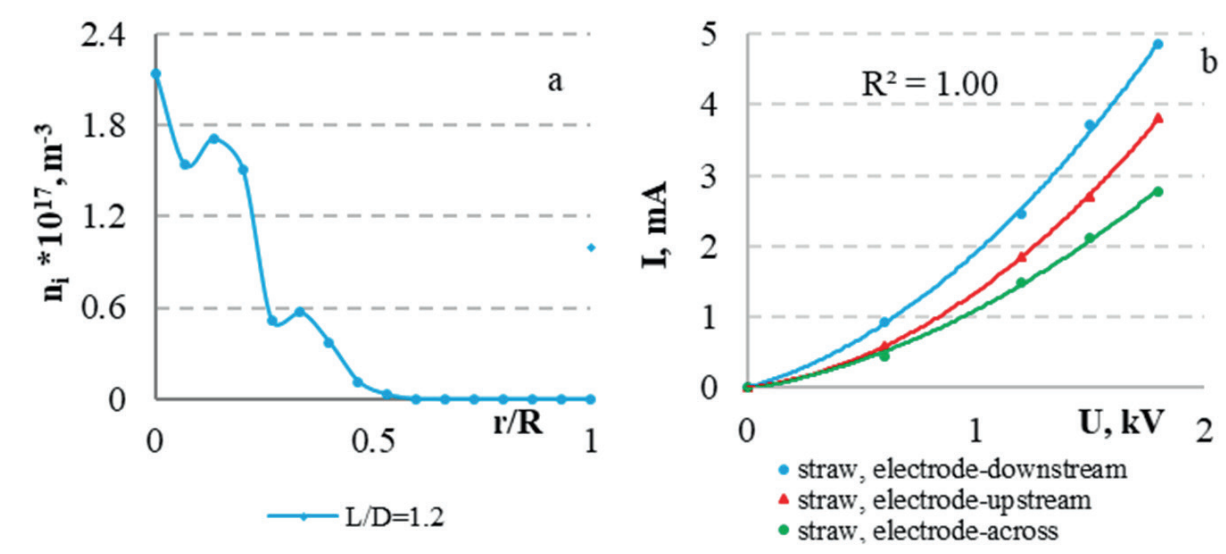

Fig. 3. The radial distribution of ion density at the thermochemical conversion of straw (a) and a current-voltage characteristic depending on the positions of electrode in swirl flame (b).

The results of the previous investigations [14], [15] have shown that the fieldinduced electric body force $(F=e n E)$, which is produced increasing the positive bias voltage of the axially inserted electrode, promotes field-enhanced drift motion of positive ions $\left(\mathrm{CHO}^{+}, \mathrm{H}_{3} \mathrm{O}^{+}, \mathrm{C}_{3} \mathrm{H}_{3}^{+}\right.$, etc. $)$ from the reaction zone outwards - to the water-cooled walls of the combustor [10].
The elastic collisions between the accelerated flame ions and neutral flame species are responsible for the formation of fieldenhanced processes of heat/mass transfer (ion wind effect) determining the variations of the local and average values of the flow velocity, flame temperature and composition. 

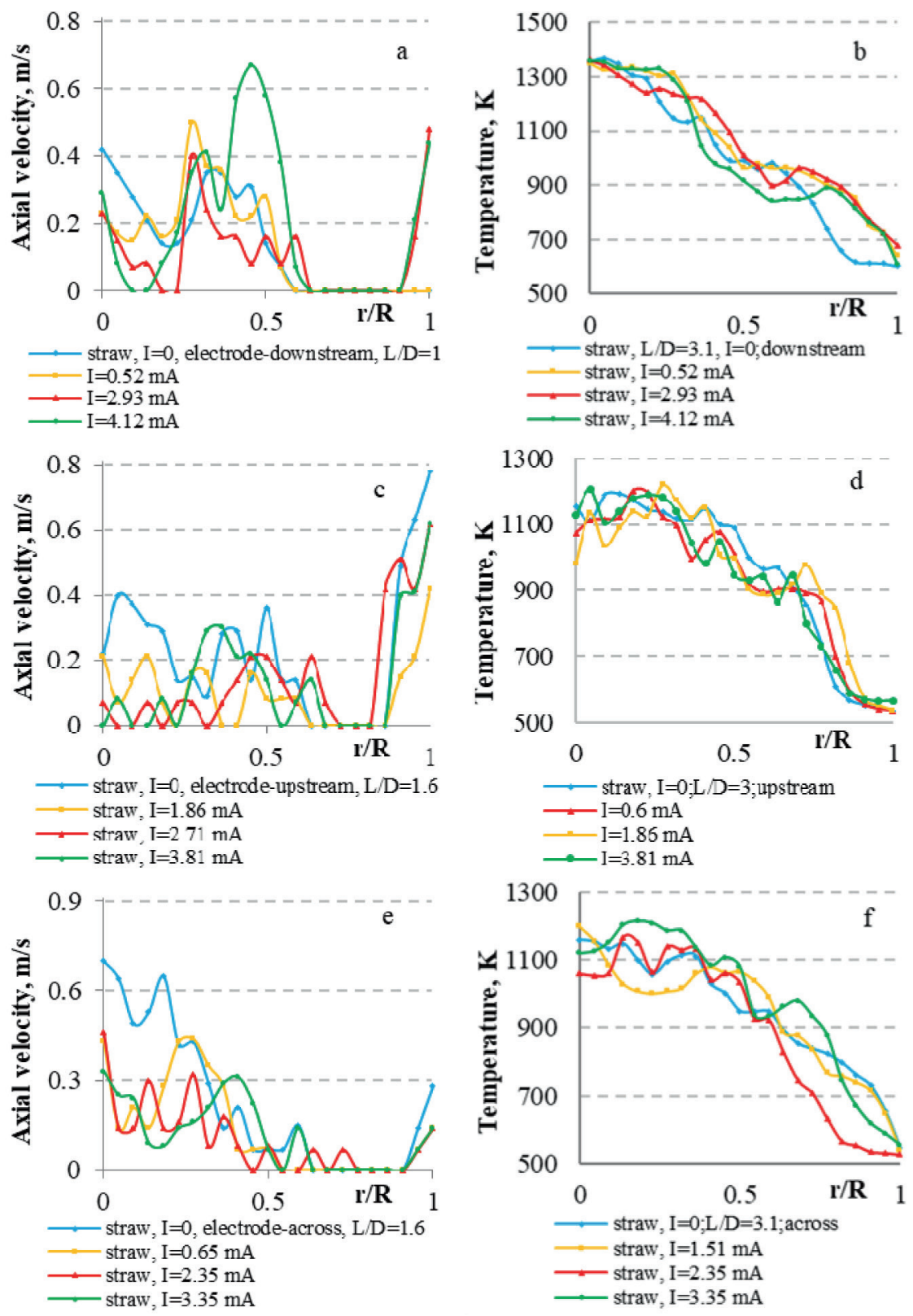

Fig. 4. The electric field effect on the formation of flow velocity and the temperature profiles of the flame reaction zone for different configurations of the electrodes.

The experimental study of the electric field effect on the main flame characteristics has shown that for the downstream position of the electrode the field-enhanced radial mass transfer of the flame ions and neutral flame species from the flame reaction zone outwards dominate. Therefore, for such electrode configuration increasing the positive bias voltage of the electrode causes the evident radial expansion of the reaction zone increasing the axial flow velocity along the airside part of the reaction zone $(r / R>0.5)$ and the flame temperature close to the walls of the combustor (Fig. 4-a, b).

For the upstream configuration of the electrode the field-enhances both the 
reverse and radial mass transfer of the flame species. The field-enhanced reverse mass transfer slows down the axial flow velocity, while the field-enhanced radial motion of the flame species promotes the radial expansion of the reaction zone (Fig. 4-c, d). If the electrode is positioned across the
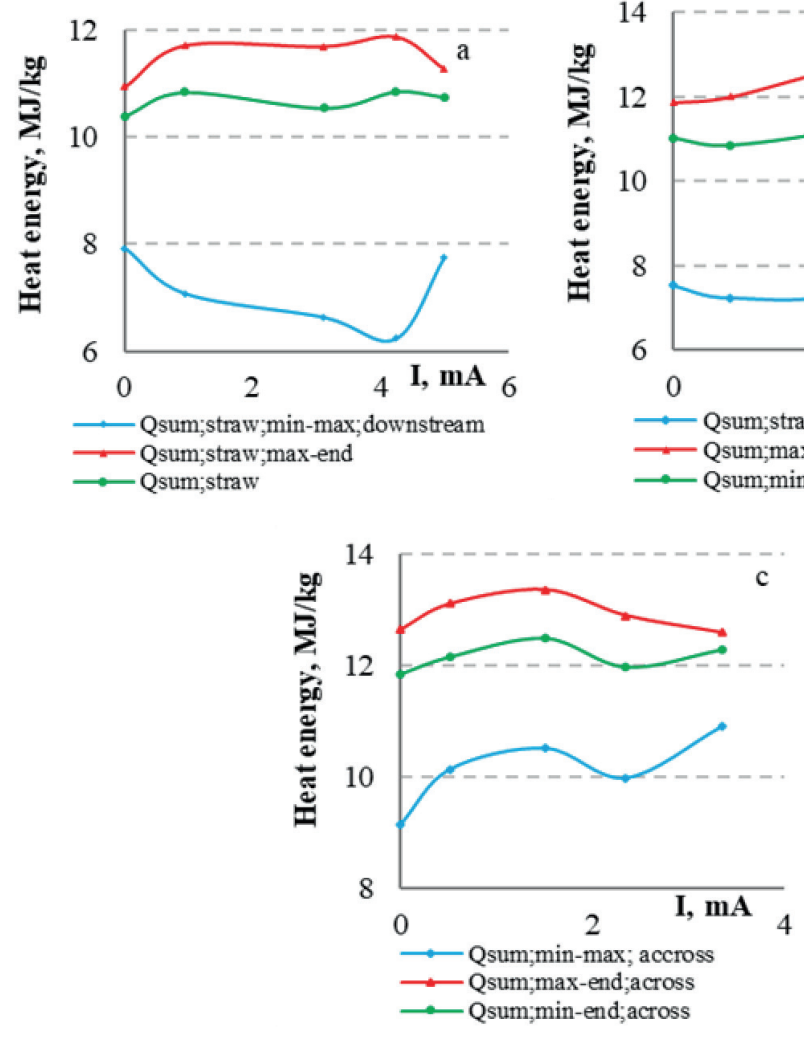

Fig. 5. The effect of electrode configuration on the total amount of the produced heat energy at the thermochemical conversion of straw.

The field-induced variations of the flow velocity and flame temperature profiles are closely linked to variations of the heat output from the device. The fieldenhanced radial expansion of the reaction zone for the downstream positioned electrode results in an increase of the heat output from the flame reaction zone by about $12.5 \%$ with an increase of the total heat output from the device by about $9.5 \%$. The produced heat energy per mass of burned straw for the downstream positioned electrode can be increased by about $12 \%$ (Fig.

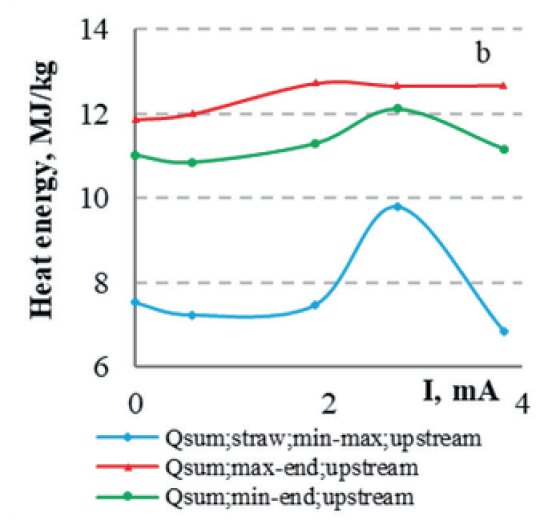

reaction zone, the electric field enhanced reverse axial mass transfer of the flame species dominates, which slows down the axial velocity close to the flow centreline $(\mathrm{r} / \mathrm{R}<$ 0.5 ) increasing the residence time of reactions and the temperature in this part of the flame (Fig. 4 - e, f). 


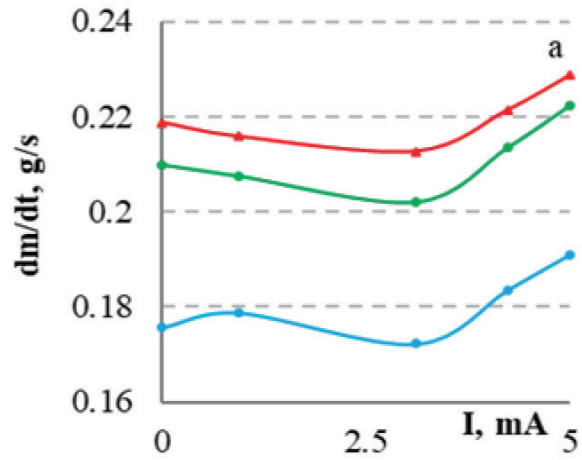

$\longrightarrow$ straw, min-max, electrode-downstream — straw;max-end

$\longrightarrow$ straw; $\min$-end
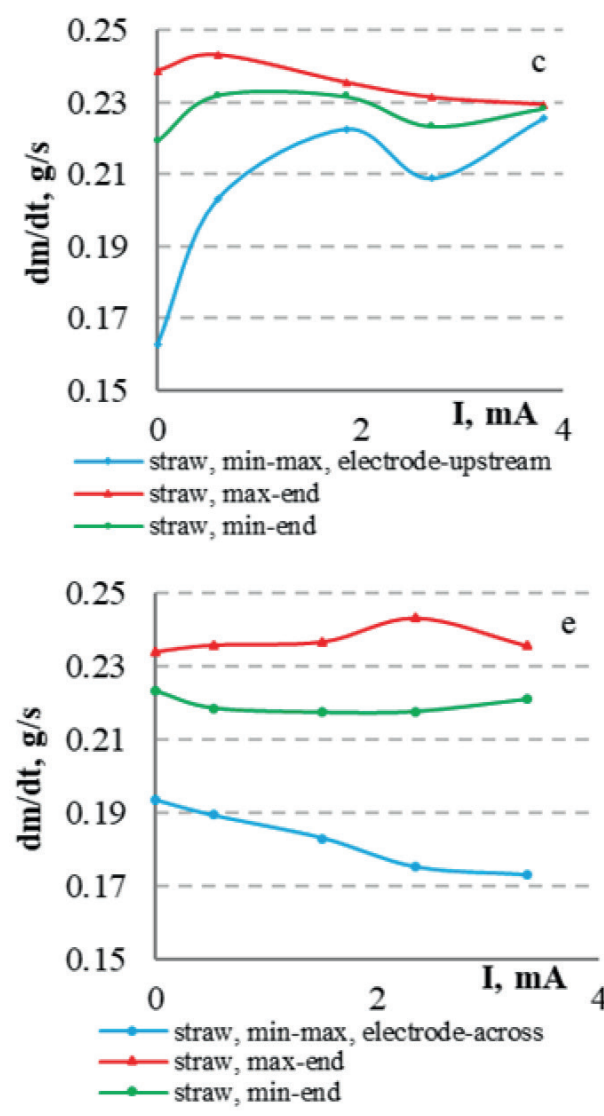
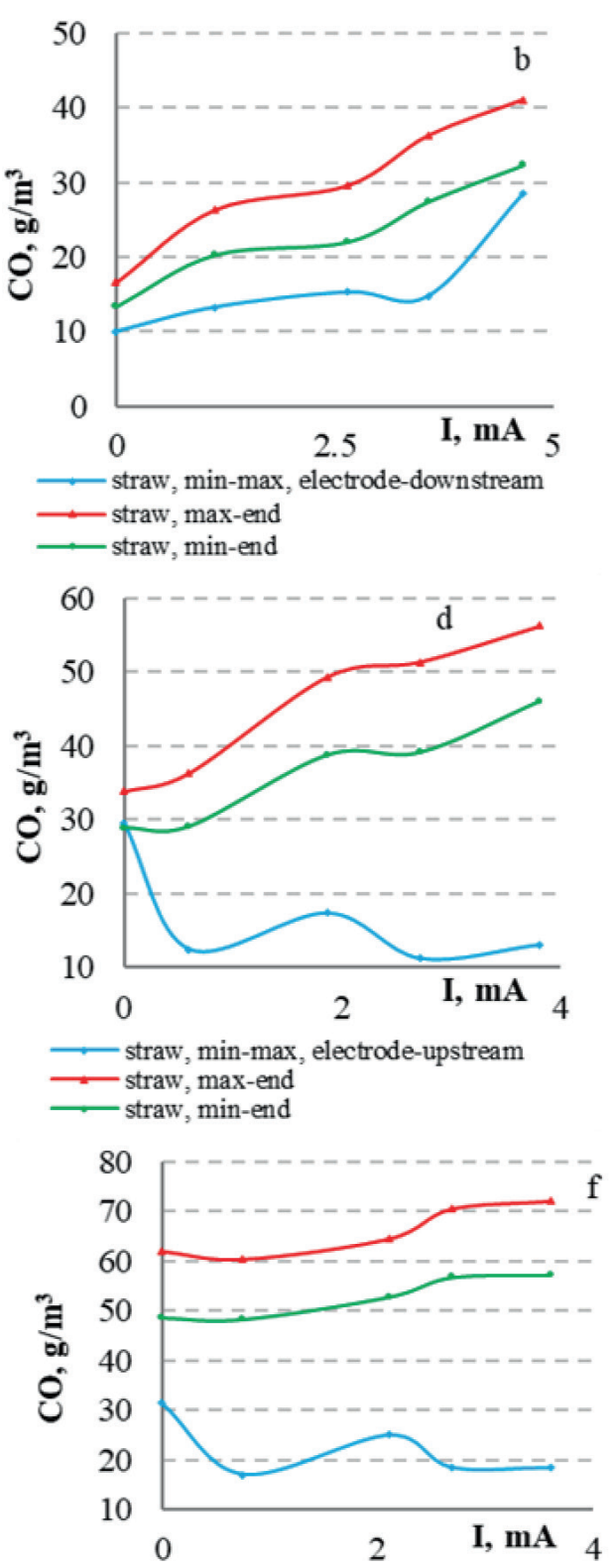

$\longrightarrow$ straw, min-max, electrode-across
straw, min-end
straw, max-end

Fig. 6. The field-induced variations of the weight loss rate of straw pellets (a, c, e) and the volume density of combustible volatiles $(\mathrm{CO})$ at the outlet of the gasifier (b, d, f) for different configurations of the electrodes.

Finally, for configuration of the electrode, located across the reaction zone, when the reverse axial heat/mass transfer of the flame species dominates, the heat output from the reaction zone increases by about $1.5 \%$ and the total heat output from the device - by about $2.3 \%$ with an increase in the produced heat energy during the burnout 
of straw by about $5.6 \%$ (Fig. 5-c). Hence, by comparing the field-induced variations of the heat output from the device, it can be concluded that upstream configuration of the electrode provides maximum heat output increase from the device and can be recommended for electrodynamic control of the produced heat power.

The analysis of the field effect on the main flame characteristics suggests that the field-induced variations of the flow dynamics, flame temperature and the heat output from the device disturb the heat balance between the flame reaction zone and the processes developing inside of the gasifier determining the complex field-induced variations of the weight loss rate and the composition of emissions at the thermal decomposition of straw pellets (Fig. 6, a-f). For the downstream configuration of the electrode an increase in the ion current provides an increase in the weight loss rate of straw pellets (Fig. 6-a) and the mass flow of volatiles increasing the mass fraction of combustible volatiles at the outlet of the gasifier (Fig. 6-b). For the upstream configuration of the electrode increasing the ion current above 2 $\mathrm{mA}$ promotes a decrease in the weight loss rate of straw pellets (Fig. 6-c), while the axial mass flow of volatiles increases (Fig. 6-d) indicating the field-induced recombination of $\mathrm{H}_{3} \mathrm{O}^{+}$and the development of the endothermic water-gas reactions, which are responsible for the field-enhanced increase of the mass flow of $\mathrm{CO}$ and $\mathrm{H}_{2}$ at the outlet of the gasifier:

$$
\begin{aligned}
& \mathrm{H}_{3} \mathrm{O}^{+}+\mathrm{e} \rightarrow \mathrm{H}_{2} \mathrm{O}+\mathrm{H} \\
& \mathrm{H}_{2} \mathrm{O}+\mathrm{C} \rightarrow \mathrm{H}_{2}+\mathrm{CO}
\end{aligned}
$$

The effect of development of the watergas reactions on the weight loss rate of straw pellets with correlating increase of mass flow of $\mathrm{CO}$ and $\mathrm{H}_{2}$ at the outlet of the gasifier is also observed if the electrode is located across the flame reaction zone (Fig. 6 - e, f) and the field-enhanced reverse mass transfer of positive ions to the carbonized surface of straw pellets slows down the thermal decomposition of straw pellets.

The field-induced variation of the flow dynamics, heat/mass transfer and residence time of reactions for different configuration of the electrodes determine the variation of the product composition. By analogy with the field effect on the produced heat energy at the thermochemical conversion of straw for all configuration of the electrodes increasing the bias voltage of the electrodes and the field-induced ion current results in an increase in the average values of the total amount of $\mathrm{CO}_{2}$ emissions in the products (by about 5-6\%) during the self-sustaining burnout of volatiles with a correlating decrease in $\mathrm{CO}$ emissions in the products (up to $60 \%$ for upstream field configuration), confirming that the electric field completes combustion of volatiles.

Besides, the flame response to fieldinduced variation of the main flame characteristics results in an increase in combustion efficiency, while the field-enhanced reverse axial and radial heat/mass transfer of the flame species from the flame reaction zone outwards with a correlating decrease in the temperature is limiting the temperature-sensitive $\mathrm{NO}$ formation, decreasing the mass fraction of $\mathrm{NO}_{x}\left(\mathrm{NO}+\mathrm{NO}_{2}\right)$ emission in the products for all electric field configurations. The maximum decrease in $\mathrm{NO}_{x}$ mass fraction (up to $10 \%$ ) was observed for upstream field configuration. Finally, the results of experiments show that the electric field control can be used as a tool to provide a cleaner and more complete thermochemical conversion of straw. 

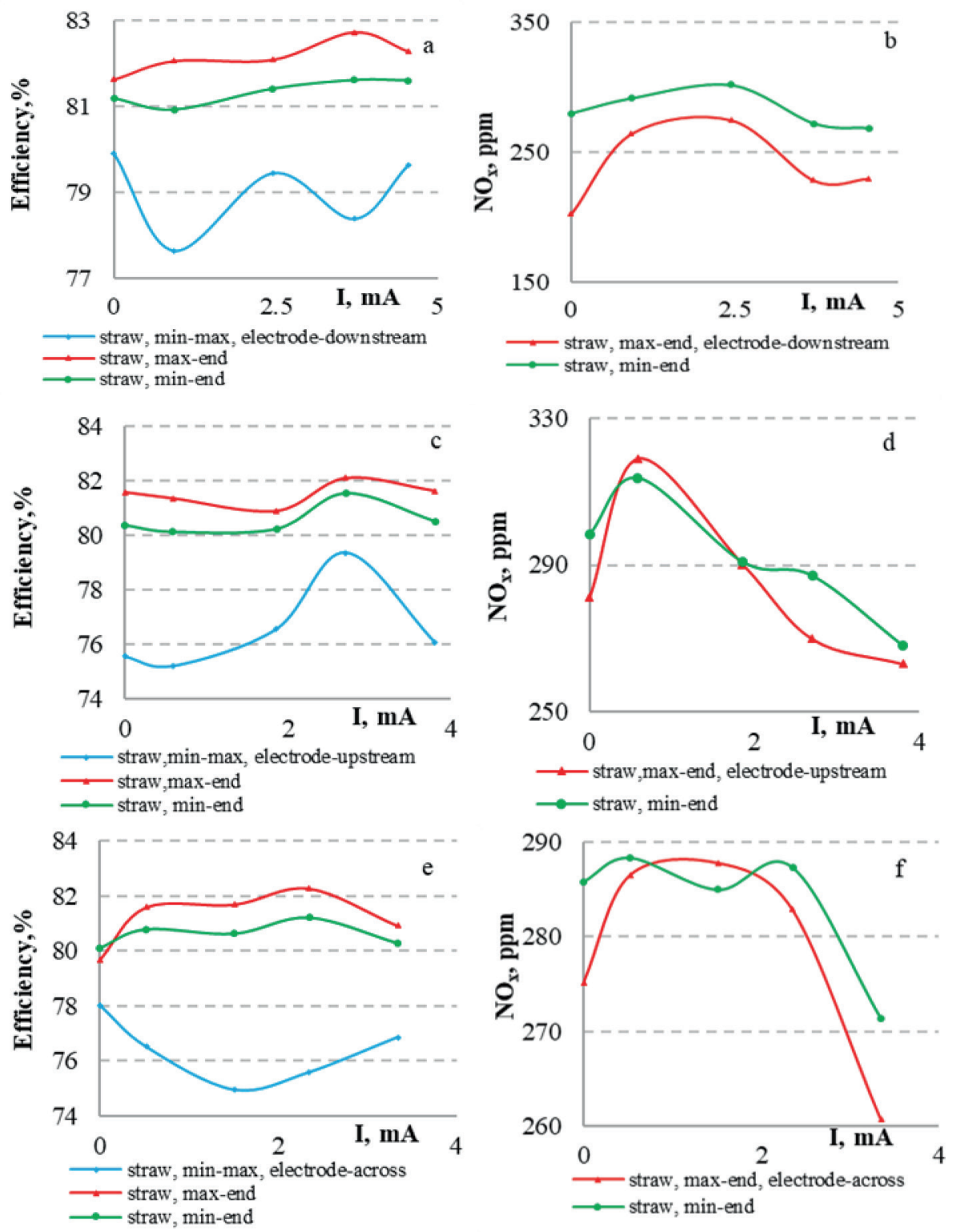

Fig. 7. The electric field effect on the combustion efficiency (a, c, e) and the mass fraction of NOx in the products $(b, d, f))$ at the thermochemical conversion of straw.

\section{CONCLUSIONS}

Summarising the results of the complex experimental studies of the DC electric field effect on the development of combustion dynamics and heat energy production during the thermochemical conversion of straw for different positions of the electrode in the flame reaction zone (downstream, upstream, across) the following conclusions are drawn:

For all positions of the electrode its 
placement in the flame flow disturbs the formation of the flame temperature and velocity profiles decreasing the average values of the axial velocity with radial expansion of the flow velocity and flame temperature profiles and enhanced burnout of volatiles. Further changes in the main flame characteristics are achieved by increasing the positive bias voltage of the electrode and the current in the flame space between the electrodes. For all positions of the electrode the DC electric field intensifies the thermal decomposition of straw pellets, enhances mixing of volatiles with air and causes changes in the main combustion characteristics by varying heat energy production and composition of the products.
The most pronounced electric field effect on the main combustion characteristics is observed for the upstream configuration of the positively biased electrode, when increasing the bias voltage from $0.6 \mathrm{kV}$ to $1.8 \mathrm{kV}$ and the ion current from $0.5 \mathrm{~mA}$ to 1.8 $\mathrm{mA}$, the heat output from the reaction zone can be increased by about $12.8 \%$, increasing the total heat output from the device by about $13.3 \%$, while the produced heat energy per mass of burned straw increases by about $10 \%$. Besides, the average volume fraction of $\mathrm{CO}_{2}$ increases by $6 \%$, decreasing the mass fraction of unburned volatiles in the products ( $\mathrm{CO}$ by about $60 \%$ and $\mathrm{H}_{2}$ by $73 \%$ ), which confirms more complete combustion of volatiles.

\section{ACKNOWLEDGEMENTS}

The authors deeply acknowledge the financial support of the European Regional
Development Funding Project No. 1.1.1.1/ 16/A/004.

\section{REFERENCES}

1. European Commission. (2019). 2030 Climate \& Energy Framework. Available at: https://ec.europa.eu/clima/policies/ strategies/2030_en

2. Roger, A.S. (2013). Comparative life cycle assessments: carbon neutrality and wood biomass energy. Resources for the Future DP13-11, Washington, 1-18. http://www. rff.org/RFF/Documents/RFF-DP-13-11.pdf

3. Vasilev, S., Baxter, D., Andersen, L.K., Vasileva, C.G., \& Morgan, T.J. (2012). An Overview of the Organic and Inorganic Phase Composition of Biomass. Fuel, 94, 1-33. https://doi.org/10.1016/j.fuel.2011. 09.030

4. Koppejan, J., \& Cremers, M. (2019). Biomass Pre-Treatment for Bioenergy. Policy report published by IEA Bioenergy. Availableat:https://www.ieabioenergy.com/
wp-content/uploads/2019/04/Pretreatment PolicyReport.pdf

5. Wang, L., Littlewood, J., \& Murphy, R.J. (2013). Environmental Sustainability of Bioethanol Production from Wheat Straw in the UK. Renewable and Sustainable Energy Reviews, 28, 715-725. https://doi. org/10.1016/j.rser.2013.08.031 , Available at:https://www.sciencedirect.com/science/ article/pii/S1364032113005716

6. Barmina, I., Kolmičkovs, A, Valdmanis, R, Vostrikovs, S., \& Zake, M. (2018). Thermo-chemical conversion of microwave activated biomass mixtures. JPCS-IOP$M M P$, Journal IOP Conf. Series: Materials Science and Engineering, doi:10.1088/1757899X/355/1/012018, Available at: https:// iopscience.iop.org/article/10.1088/1757$899 X / 355 / 1 / 012018$ 
7. Barmina I., Valdmanis R., \& Zake M. (2018). The Effects of Biomass Co-Gasification and Co-Firing on the Development of Combustion Dynamics. Energy, 146, 4-12. DOI: 10.1016/j.energy.2017.04.140

8. Pedersen, L.S., Nielsen, H.P., Kiil, S., Hansen, L.A., Dam-Johansen, K., Kildsig, F., ... \& Jespersen, P. (1996). Full-Scale Co-Firing of Straw and Coal. Fuel, 75, 1584-1590. https://doi.org/10.1016/00162361(96)82642-1

9. Houshfar, E., Løvås, T., \& Skreiberg, Ø (2012). Experimental Investigation on NOx Reduction by Primary Measures in Biomass Combustion: Straw, Peat, Sewage Sludge, Forest Residues and Wood Pellets. Energies, 5, 270-290; doi:10.3390/en5020270.

10. Lawton, J., \& Weinberg, F. (1969). Electrical aspects of combustion. Oxford, UK: Clarendon Press, ISBN 0198553412.

11. Blades, A.T. (1976). Ion Formation in Hydrocarbon Flames. Can J Chem, 54 (18), 2919-2924, https://www.nrcresearchpress. com/doi/pdfplus/10.1139/v76-413

12. Chien, Y., \& Dunn-Rankin, D. (2018). Electric Field Induced Changes of a Diffusion Flame and Heat Transfer near an Impinging Surface, Energies, 11, 1235; doi:10.3390/en11051235.

13. Ryu, S.K., Kim, Y.K., Kim, M.K., Won, S.H., \& Chung, S.H. (2010). Observation of Multi-Scale Oscillation of Laminar Lifted Flames with Low-Frequency AC Electric Fields. Combust. Flame, 157, 25-32. https://doi.org/10.1016/j. combustflame.2009.10.001 Available at: https://www.sciencedirect.com/science/ article/abs/pii/S001021800900279X
14. Barmina, I., Kolmickovs, A., Valdmanis, R., Zake, M., Vostrikovs, S., Kalis, H., \& Strautins, U. (2019). Electric Field Effect on the Thermal Decomposition and Cocombustion of Straw with Solid Fuel Pellets, Energies, 12, 1522; https://oi.org/10.3390/ en 12081522

15. Barmina, I., Purmalis, M., Valdmanis, R., \& Zakse, M. (2016). Electrodynamic Control of the Combustion Characteristics and Heat Energy Production. Combustion Science and Technology, 188 (2), 190-206, DOI: 10.1080/00102202.2015.1088010. URL: http://www.tandfonline.com/doi/full/10.10 80/00102202.2015.1088010

16. Colannino, J. (2013). Electrodynamic Combustion Control TM Technology, A ClearSign White Paper; ClearSign Combustion Cooperation: Seattle, WA, USA. Available at: http://www.ctgn.qc.ca/ images/bulletins/bulletin_vol4no3/pdf/ind ha_clearsign_01.pdf

17. Greene, S.A. (1963). A Literature Survey of Ions in Flames, Report No. TDR169(S3153-01) TN-5, Ballistic Systems Division Air Force Systems Command, United States Air Force, California, 1-23.

18. Yang, H., Yan, R., Chen, H, Lee, D.H, \& Zheng, Ch. (2007). Characteristics of Hemicellulose, Cellulose and Lignin Pyrolysis, Fuel, 86, 1781-1799. https://doi. org/10.1016/j.fuel.2006.12.013

19. Barmina, I., Kolmickovs, A., Valdmanis, R., \& Vostrikovs, S. (2019). Electrodynamic control of straw co-firing with propane. In Engineering for Rural Development conf, 22-24 May 2019 (pp. 1319-1324), Jelgava, Latvia: Latvia University of Life Sciences and Technologies. DOI: 10.22616/ ERDev2019.18. N022. 